\title{
5-Azacytidine suppresses the proliferation of pancreatic cancer cells by inhibiting the Wnt/ $\beta$-catenin signaling pathway
}

H. Zhang', W.C. Zhou ${ }^{1}$, X. Li ${ }^{1}$, W.B. Meng' ${ }^{1}$ L. Zhang ${ }^{1}$, X.L. Zhu', K.X. Zhu' ${ }^{1}$, Z.T. Bai ${ }^{1}$, J. Yan' ${ }^{1}$, T. Liu' ${ }^{2}$ X.C. Xu' ${ }^{2}$ and Y.M. Li ${ }^{2}$

'Department II of General Surgery, The First Hospital of Lanzhou University, Hepatopancreatobiliary Surgery Institute of Gansu Province, Clinical Medical College Cancer Center of Lanzhou University, Lanzhou, China ${ }^{2}$ General Surgery, The Second Hospital of Lanzhou University, Lanzhou, China

Corresponding author: Y.M. Li

E-mail: liymingcn@163.com

Genet. Mol. Res. 13 (3): 5064-5072 (2014)

Received February 3, 2014

Accepted May 12, 2014

Published July 4, 2014

DOI http://dx.doi.org/10.4238/2014.July.4.22

ABSTRACT. 5-Azacytidine has been shown to be an effective anti-
pancreatic cancer drug, but the mechanism remains unknown. In the
current study, we explored the effect of 5-azacytidine on abnormal
activation of the Wnt- $\beta$-catenin signaling pathway in pancreatic
cancer cells. The human pancreatic cancer cell line Bxpc-3 was treated
with different concentrations of 5-azacytidine for various times. The
proliferation and early apoptosis of the cells were evaluated using the
CCK 8 method and flow cytometry, respectively. mRNA and protein
expression of $\beta$-catenin, c-myc, and cyclinD1 were detected using real-
time fluorescent quantitative polymerase chain reaction and Western blot
analysis, respectively. The proliferation of Bxpc-3 cells was suppressed
by 5-azacytidine. The early apoptosis of the cells was significantly
enhanced over time and with increasing drug concentrations. The
expression of $\beta$-catenin, c-myc, and cyclinD1 were down-regulated,
showing significant differences between different concentrations and 
treatment times $(\mathrm{P}<0.05)$. 5-Azacytidine suppressed the proliferation of pancreatic cancer cells by inhibiting the $\mathrm{Wnt} / \beta$-catenin signaling pathway, particularly the expression of $\beta$-catenin, c-myc, and cyclinD1. This study may provide a new potential strategy for diagnosing and treating pancreatic cancer.

Key words: 5-Azacytidine; c-Myc; CyclinD1; Pancreatic cancer; Wnt $/ \beta$-catenin

\section{INTRODUCTION}

Pancreatic cancer is a digestive malignancy with poor prognosis; most deaths occur within 7 years after operation because of neoplasm recurrence (Garcea et al., 2008). Although resection is a preferred treatment method for this condition, drug therapy continues to serve as a major treatment method for patients suffering from unresectable advanced pancreatic cancer (Hackert and Büchler, 2013; Jagou-Yuschak et al., 2013).

5-Azacytidine was originally used for effective treatment of myelodysplastic syndrome. Recent studies have demonstrated that this drug also has anti-tumor effects. Numerous studies have been conducted to examine its effect on pancreatic cancer, as well as the associated mechanisms. The human runt-related transcription factor 3 ( $R U N X 3)$ gene is methylated in pancreatic cancer tissue, which is significantly related to the occurrence and development of pancreatic cancer; 5-azacytidine suppresses the growth of MIApaca2 cells (a human pancreatic cancer cell line) by reversing RUNX3 methylation (Jagou-Yuschak et al., 2013). 5-Azacytidine up-regulates miR-33a expression to alter the biological characteristics of pancreatic cancer stem cells; such intervention weakens the migration and invasion capabilities of cells and enhances their susceptibility to anti-tumor drugs in in vitro experiments (Han et al., 2013). The highly frequent methylation of $\mathrm{CpG}$ islands of the TNFRSF10C promoter leads to gene inactivation and enhances tumor cell growth in most pancreatic cancer cell lines; 5-azacytidine greatly increases the transcriptional level of TNFRSF10C (except CFPAC-1) (Nalls et al., 2011). 5-Azacytidine may also prevent the growth of pancreatic cancer cells by influencing signaling pathways. However, few studies have been conducted to examine this mechanism.

The $\mathrm{Wnt} / \beta$-catenin pathway is a genetically conserved signaling pathway, which is associated with a variety of human diseases such as birth defects and tumors. As an essential signaling pathway, it regulates cell proliferation and polarity, as well as cell differentiation during embryonic development. Its abnormal activation is closely related to the development of a variety of cancers (Cai et al., 2011). Abnormal $\beta$-catenin expression plays an important role in human pancreatic cancer; it up-regulates the expression of cyclinD1, c-myc, and matrix metalloprotease-7, causing the degradation of extracellular matrix and, consequently, leading to uncontrolled cell proliferation and differentiation (Clevers, 2006). CyclinD1 and $c$-myc are 2 critical target genes of the Wnt signaling pathway. Their amplification and/or overexpression are extremely common in tumor cells, and their activation may play an essential role in carcinogenesis (Abba et al., 2004; Wang et al., 2013). However, whether their expression is associated with the mechanism of 5-azacytidine in treating pancreatic cancer remains to be explored.

In this study, we investigated the effect of 5-azacytidine on pancreatic cancer and ex- 
plored the mechanisms underlying this effect. The protein and mRNA expression of $\beta$-catenin, c-myc, and cyclinD1 were detected using Western blot analysis and real-time fluorescent quantitative polymerase chain reaction (RT-qPCR), respectively. Cell proliferation was detected using the CCK8 method. Early apoptosis of cells was tested using flow cytometry.

\section{MATERIAL AND METHODS}

\section{Materials}

The human pancreatic cancer cell line Bxpc-3 was purchased from the Type Culture Collection of the Chinese Academy of Sciences (Shanghai, China). 5-Azacytidine was purchased from Sigma (St. Louis, MO, USA). Kits for RT-qPCR, Taq enzyme, dNTPs, and PCR primers were purchased from TaKaRa (Shiga, Japan). CCK8 kits were purchased from the Beyotime Institute of Biotechnology (Shanghai, China). Annexin V-fluorescein isothiocyanate (FITC)/propidium iodide (PI) apoptosis detection kits were purchased from BD Biosciences (Franklin Lakes, NJ, USA).

\section{Cell culture and treatment}

Bxpc-3 cells were cultured in Dulbecco's modified Eagle's medium (DMEM) containing 10\% fetal calf serum (FCS; Gibco; Grand Island, NY, USA) in $5 \% \mathrm{CO}_{2}$ at $37^{\circ} \mathrm{C}$ at a density of $5 \times 10^{5}$ cells $/ \mathrm{mL}$. Cells in logarithmic growth phase were harvested. They were inoculated in a $25-\mathrm{cm}^{2}$ flask until adherence. The cells were cultured with DMEM containing 0,5 , and $10 \mu \mathrm{M} 5$-azacytidine and serum-free DMEM for 24, 48, and $72 \mathrm{~h}$, respectively. Total mRNA and protein were extracted. The cells that were not treated with 5-azacytidine comprised the control group.

\section{Cell proliferation}

Cell proliferation and viability were detected using the CCK8 method according to the kit protocol. Cells were seeded $1 \times 10^{4}$ cells $/ \mathrm{mL}$ on 96 -well plates and cultured in $5 \% \mathrm{CO}_{2}$ at $37^{\circ} \mathrm{C}$ for $24 \mathrm{~h}$. They were then treated with 5 -azacytidine at 0,5 , and $10 \mu \mathrm{M}$ for 24,48 , and 72 $\mathrm{h}$, respectively. Drug-free DMEM was used as a control and the no-cell wells with the same amounts of 5-azacytidine were used as blank controls. The media were replaced every $24 \mathrm{~h}$. After treatment, CCK8 and the plates were incubated for $2 \mathrm{~h}$. Absorbance $(A)$ was read at 450 $\mathrm{nm}$ and cell viability (\%) was calculated based on the following formula:

$$
\text { Cell viability }(\%)=[A(\text { dose })-A \text { (blank })] /[(A(0 \text { dose })-A(\text { blank })] \text { x } 100 \%
$$

\section{Flow cytometry}

Flow cytometry was performed to analyze cell apoptosis. Cells at a density of $8 \mathrm{x}$ $105 / \mathrm{mL}$ were cultured in $10 \%$ FCS-containing DMEM with 0,5 , and $10 \mu \mathrm{M} \mathrm{5}$-azacytidine for 24,48 , and $72 \mathrm{~h}$, respectively. Cells were collected after trypsinization, and then fixed in $70 \%$ ethanol. Ethanol was removed. The samples were stained with $50 \mu \mathrm{g} / \mathrm{mL}$ FITC, An- 
nexin V, and PI (BD Biosciences), respectively. Cells in early apoptosis were assayed using an FACScan flow cytometry apparatus (BD Biosciences). All steps were conducted according to manufacturer instructions.

\section{RT-qPCR}

The expression of $\beta$-catenin, $c$-myc, and cyclinD1 was detected by RT-qPCR. Cells were cultured in DMEM containing 0, 5, and $10 \mu \mathrm{M}$ 5-azacytidine for 24,48 , and $72 \mathrm{~h}$, respectively. Total RNA was extracted according to kit instructions (TaKaRa). After integrity identification, reverse transcription was performed to convert RNA to cDNA according to kit instructions (Primescript ${ }^{\mathrm{TM}} \mathrm{RT}$ reagent kit; TaKaRa). $\beta$-actin was used as an internal standard. The total reaction system of $25 \mu \mathrm{L}$ (SYBR ${ }^{\circledR}$ Premix Ex Taq ${ }^{\mathrm{TM}}$ II kit; TaKaRa) contained 12.5 $\mu \mathrm{L}$ SYBR $^{\circledR}$ Premix Ex Taq II, $1 \mu \mathrm{L}$ upstream primer, $1 \mu \mathrm{L}$ downstream primer, $1.0 \mu \mathrm{L}$ ROX Reference, $1 \mu \mathrm{L}$ cDNA, and $6.0 \mu \mathrm{L} \mathrm{ddH}_{2} \mathrm{O}$. The PCR cycle was 37 cycles. The primer sequences and annealing temperatures are summarized in Table 1.

\begin{tabular}{llr}
\multicolumn{2}{c}{ Table 1. Primer sequences used to amplify genes. } \\
\hline Primer & Sequence & Annealing temperature $\left({ }^{\circ} \mathrm{C}\right)$ \\
\hline$\beta$-catenin & Forward: 5'-GAGTGCTGAAGGTGCTATCTGTCTG-3' & 56 \\
& Reverse: 5'-GTTCTGAACAAGACGTTGACTTGGA-3' & 56 \\
cyclinD1 & Forward: 5'-CCTGGTGCTCCATGAGGAGA-3' & 57 \\
$\beta$-actin & Reverse: 5'-CTCCAGCAGAAGGTGATCCAGA-3' \\
& Forward: 5'-ATGTTCGTGGCCTCTAAGATGA-3' \\
& Reverse: 5'-CAGGTTCCACTTGAGCTTGTTC-3' & 56 \\
\hline
\end{tabular}

\section{Western blot analysis}

Protein expression of $\beta$-catenin, c-myc, and cyclinD1 was observed using Western blotting. After treatment with 5-azacytidine, ice-cold RIPA buffer (1\% Nonidet P-40 (NP40), $50 \mathrm{mM}$ Tris, $150 \mathrm{mM} \mathrm{NaCl}, 0.25 \%$ deoxycholate, $1 \mathrm{mM}$ EGTA, $1 \mathrm{mM} \mathrm{NaF}$ ) and $1 \mu \mathrm{L}$ protease inhibitor cocktail (Sigma) were added to the samples. The samples were incubated on ice for $20 \mathrm{~min}$ and then centrifuged at 20,000 $\mathrm{g}$ for $10 \mathrm{~min}$. The supernatants were collected. Lowry assays (Bio-Rad; Hercules, CA, USA) were performed for protein quantification. Equal amounts of proteins were subjected to $8 \%$ sodium dodecyl sulfatepolyacrylamide gel electrophoresis at $120 \mathrm{~V}$ and then were transferred to polyvinylidene fluoride membranes (Millipore; Billerica, MA, USA) at $120 \mathrm{~V}$ for $45 \mathrm{~min}$ (according to molecular weight). After blocking in 3\% bovine serum albumin or $5 \%$ milk, the membranes were incubated in anti- $\beta$-catenin (dilution, 1:1000; Abcam; Cambridge, UK), anti-c-myc (1:1000; Abcam), and anti-cyclinD1 $\left(1: 1000\right.$; Abcam) antibodies overnight at $4^{\circ} \mathrm{C}$. After being washed for 5 min 3 times in Tris-buffered saline containing Tween 20, membranes were incubated in the suitable secondary antibody (1:4000; Abcam) at room temperature for $2 \mathrm{~h}$. After washing with Tris-buffered saline containing Tween 20, they were developed using enriched chemiluminescence. Photos were acquired using a gel imaging analysis system (VersaDoc4000; Bio-Rad). 


\section{Statistical analysis}

Data are reported as means \pm standard deviation and were processed using SPSS 17.0 (SPSS Inc., Chicago, IL, USA). The paired Student $t$-test or the F-test was used to compare groups. Differences in $\mathrm{P}<0.05$ were considered to be statistically significant.

\section{RESULTS}

\section{Cell proliferation}

Cell proliferation was detected using the CCK8 kit. 5-Azacytidine inhibited the proliferation of Bxpc-3 cells in time- and concentration-dependent manners. The results are shown in Figure 1.

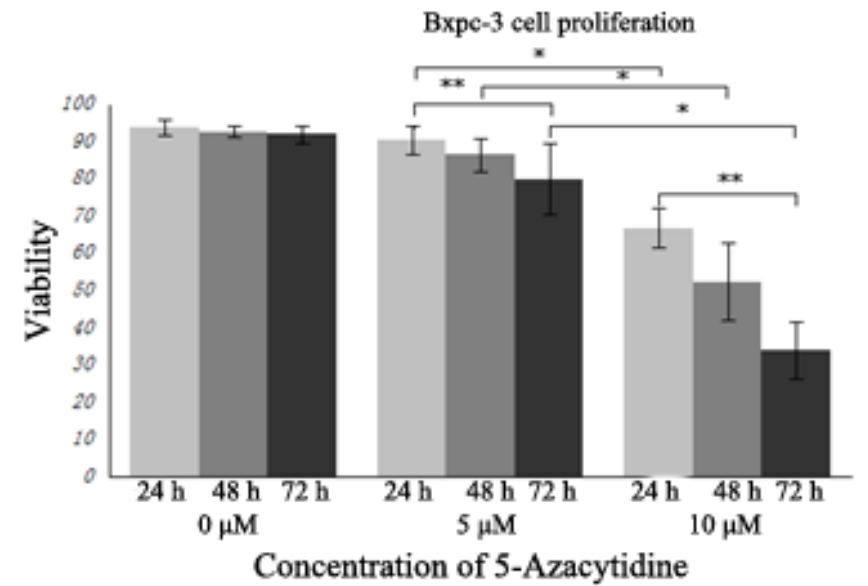

Figure 1. Bxpc-3 proliferation in different groups. Results were analyzed using the F-test: $* \mathrm{P}<0.05 v s$ the groups of different concentrations at the same time $\left(P_{24 \mathrm{~h}}=0.011 ; \mathrm{P}_{48 \mathrm{~h}}=0.008 ; \mathrm{P}_{72 \mathrm{~h}}=0.006\right) ; * \mathrm{P}<0.05 v s$ the groups of different treatment times with the same drug concentration $\left(\mathrm{P}_{5 \mu \mathrm{M}}=0.023 ; \mathrm{P}_{10 \mu \mathrm{M}}=0.014\right)$.

\section{Early apoptosis}

Early apoptosis of the Bxpc-3 cells was determined using flow cytometry. In the $0 \mu \mathrm{M}$ group, the apoptotic rate of early apoptosis was $0.07 \pm 0.02-0.16 \pm 0.03 \%$. In the $5 \mu \mathrm{M}$ group, the rates were significantly increased compared with the control group $(\mathrm{P}<0.001)$. When the concentration of 5 -azacytidine increased to $10 \mu \mathrm{M}$, significantly higher apoptotic rates were observed compared with those in the $5 \mu \mathrm{M}$ group $(\mathrm{P}<0.001)$ (Table 2$)$.

Table 2. Bxpc-3 early apoptosis with 5-azacytidine treatment (F-test).

\begin{tabular}{lcccc}
\hline 5-Azacytidine & $0 \mathrm{mM}$ & $5 \mathrm{mM}$ & $10 \mathrm{mM}$ & $\mathrm{P}^{*}$ \\
\hline $24 \mathrm{~h}$ & $0.07 \pm 0.02 \%$ & $1.8 \pm 0.24 \%$ & $3.95 \pm 0.47 \%$ & $<0.001$ \\
$48 \mathrm{~h}$ & $0.11 \pm 0.05 \%$ & $15.3 \pm 0.83 \%$ & $13.66 \pm 2.11 \%$ & $<.001$ \\
$72 \mathrm{~h}$ & $0.16 \pm 0.03 \%$ & $1.87 \pm 0.62 \%$ & $28.23 \pm 3.54 \%$ & $<0.001$ \\
$\mathrm{P} * *$ & 0.032 & $<0.001$ & $<0.001$ \\
\hline
\end{tabular}




\section{mRNA levels}

mRNA levels were detected using RT-qPCR. As drug dosage and treatment time increased, $\beta$-catenin expression noticeably decreased $(\mathrm{P}=0.019$ and $\mathrm{P}=0.004)$. In the $10 \mu \mathrm{M}$ group, $\beta$-catenin expression significantly decreased after $24 \mathrm{~h}$ of treatment compared with the control group $(\mathrm{P}=0.023)$. However, at the same drug concentration, no significant difference was observed in $\beta$-catenin expression between the 48 and $72 \mathrm{~h}$ groups $(\mathrm{P}>0.05)$. 5-Azacytidine significantly inhibited cyclinD1 expression. In the $10 \mu \mathrm{M}$ group, cyclinD1 expression showed a significant decrease compared with the control group $(\mathrm{P}=0.023)$. However, at the same drug concentration, no significant difference was observed between the 48 and $72 \mathrm{~h}$ groups $(\mathrm{P}>0.05)$. 5-Azacytidine significantly down-regulated $c$-myc mRNA expression in time- and concentration-dependent manners $(\mathrm{P}<0.05)$. The results are shown in Figure 2.

A

B-catenin mRNA in Bxpc-3 cell

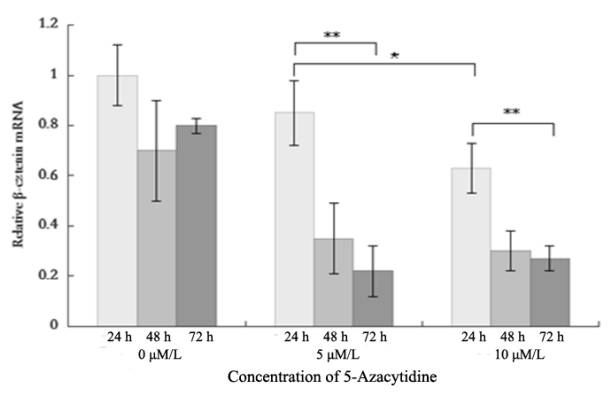

B



C



Figure 2. mRNA levels of $\beta$-catenin, c-myc, and cyclinD1 in Bxpc-3 cells after different times of treatment and with different concentrations of 5-azacytidine. A. $\beta$-catenin. B. cyclinD1. C. c-myc. * and ** indicate significant differences. 


\section{Protein expression}

The results of Western blot analysis are shown in Figure 3. In the $0 \mu \mathrm{M}$ group, $\beta$-catenin, a key factor in the $\mathrm{Wnt} / \beta$-catenin signal pathway, was activated and $\mathrm{c}$-myc and cyclinD1 were highly expressed. After treatment with 5-azacytidine, protein expression was significantly inhibited. At $72 \mathrm{~h}$, cyclinD1 protein expression significantly decreased compared to that in groups treated with different concentrations of 5-azacytidine.



Figure 3. Protein expression of $\beta$-catenin, c-myc, and cyclinD1 in Bxpc-3 cells using Western blotting.

\section{DISCUSSION}

The development of pancreatic cancer is a process in which multiple genes participate (Iwaya et al., 2003; Abba et al., 2004). In this study, we investigated the effect of 5 -azacytidine on pancreatic cancer and then explored the potential mechanism responsible for the effect.

Recent studies have shown that 5 -azacytidine possesses anti-tumor bioactivity. It up-regulates the expression level of $M A G E-A 4$ to immunologically intervene and inhibit the proliferation of thyroid cancer cell lines such as 8505c, HTh7, BCPAP, and TPC-1 (Gunda et al., 2013). In experiments examining mice with different tumors, 5-azacytidine increased the susceptibility of myeloid-derived suppressor cells to cyclophosphamide in the spleen and tumor microenvironment, which may benefit the long-term prognosis of patients with tumors (Mikysková et al., 2014). It inhibits the migration and invasion of the esophagus cancer cell line TE-1 by up-regulating $R U N X 3$ expression (Wang et al., 2013). In this study, the results showed that 5-azacytidine suppressed the proliferation of Bxpc-3 cells and promoted their early apoptosis in both time- and concentration-dependent manners $(24,48$, and $72 \mathrm{~h}$ and 5-10 $\mu \mathrm{M}$, respectively). These results are consistent with those of previous studies and further support the anti-pancreatic cancer activity of 5-azacytidine.

The Wnt/ $\beta$-catenin pathway plays an essential role in the development of pancreatic cancer. Inhibition of the pathway markedly influences the development of pancreatic acini (rather than islet cells). Abnormal activation of the Wnt/ $\beta$-catenin pathway has been re- 
ported in diverse carcinomas such as pancreatic cancer, lung cancer, colorectal cancer, liver cancer, and melanoma (Murtaugh et al., 2005; Dessimoz et al., 2005). Activation of the Wnt signaling pathway promotes the migration and metastasis of pancreatic ductal adenocarcinoma and Wnt molecules, including WNT2b, WNT7b, and WNT11 (Da Forno et al., 2008; Morris et al., 2010). Activation of the Wnt signaling pathway contributes to the progression of pancreatic ductal adenocarcinoma (Wang et al., 2009). The Wnt5A-NFAT pathway mediates the apoptosis tolerance of pancreatic cancer cells (Griesmann et al., 2013). $\beta$-catenin expression is closely associated with tumor-like changes and malignant transformation of pancreatic ductal epithelial cells (Jones et al., 2008). Abnormal activation of the Wnt/ $\beta$ catenin pathway aggravates the development, metastasis, and drug resistance of pancreatic cancer (Morris et al., 2010). Similarly to the known aberrant methylation in other tumors, aberrant methylation of $\mathrm{Wnt} / \beta$-catenin-associated factors is commonly observed in pancreatic cancer, such as exacrinous factors WNT5a, WNT7A, WNT9A and cellular surface receptors FZD9, cytoplasmic transducer APC2, the nuclear factors SOX1, SOX7, SOX14, and SOX17, and the pathway inhibitors FRZB, SFRP1, SFRP2, KREMEN2, NKD2, and WIF1. Although the genes FZD9, APC2, SOX1, SOX3, SOX11, FRZB, and KREMEN2 have not been observed at abnormal levels, 5-azacytidine can up-regulate their expression, indicating that aberrant methylation of certain genes may influence the expression (Jones et al., 2008; Vincent et al., 2011). In this study, we investigated the effects of 5-azacytidine on the proliferation and early apoptosis of pancreatic cancer cells and the expression of key molecules involved in the $\mathrm{Wnt} / \beta$-catenin pathway, namely $\beta$-catenin, c-myc, and cyclinD1. Our results showed that 5-azacytidine greatly suppressed the proliferation of Bxpc-3 cells in time- and dose-dependent manners and inhibited the expression of key molecules involved in the $\mathrm{Wnt} / \beta$-catenin pathway. These findings are consistent with those reported in previous studies and suggest that 5 -azacytidine promotes the early apoptosis and proliferation of pancreatic cancer cells by inhibiting the expression of $\beta$-catenin, c-myc, and cyclinD1, at least partially.

There were some limitations to this study. First, aberrant methylation may not completely account for the complex activities of 5-azacytidine on tumor cells. The mechanisms behind the effect of 5-azacytidine on tumor cells remain to be investigated. Second, the data in this study were acquired only from the Bxpc-3 cell line. Therefore, we could not confirm the same changes in cellular factors in other pancreatic cancer cells. To overcome this limitation, additional pancreatic cancer cell lines should be investigated. Finally, this study was an in vitro experiment. The actual microenviroment in vivo may be different. Therefore, to confirm the results obtained in this study, further animal experiments are necessary.

The expression of the key factors in the Wnt/ $\beta$-catenin pathway, such as $\beta$-catenin, c-myc, and cyclinD1, is down-regulated by 5-azacytidine at the mRNA and protein levels, preventing the development of pancreatic cancer. This study may provide new evidence to investigate the anti-tumor mechanism of the effect of 5-azacytidine on tumor cells, as well as the drug resistance of tumor cells. In addition, our results may provide a foundation for molecule-targeted therapy for tumors based on the Wnt/ $\beta$-catenin pathway.

\section{Conflicts of interest}

The authors declare no conflict of interest. 


\section{ACKNOWLEDGMENTS}

Research supported by the Fundamental Research Funds for the Central Universities (\#lzujbky-2012-163), the West Light Foundation of the Chinese Academy of Science (\#2011180), and the Gansu Provincial Natural Science Foundation (\#1208RJZA296).

\section{REFERENCES}

Abba MC, Laguens RM, Dulout FN and Golijow CD (2004). The c-myc activation in cervical carcinomas and HPV 16 infections. Mutat. Res. 557: 151-158.

Cai HH, Sun YM, Miao Y, Gao WT, et al. (2011). Aberrant methylation frequency of TNFRSF10C promoter in pancreatic cancer cell lines. Hepatobiliary Pancreat. Dis. Int. 10: 95-100.

Clevers H (2006). Wnt/beta-catenin signaling in development and disease. Cell 127: 469-480.

Da Forno PD, Pringle JH, Hutchinson P, Osborn J, et al. (2008). WNT5A expression increases during melanoma progression and correlates with outcome. Clin. Cancer Res. 14: 5825-5832.

Dessimoz J, Bonnard C, Huelsken J and Grapin-Botton A (2005). Pancreas-specific deletion of beta-catenin reveals Wntdependent and Wnt-independent functions during development. Curr. Biol. 15: 1677-1683.

Garcea G, Dennison AR, Pattenden CJ, Neal CP, et al. (2008). Survival following curative resection for pancreatic ductal adenocarcinoma. A systematic review of the literature. JOP 9: 99-132.

Griesmann H, Ripka S, Pralle M, Ellenrieder V, et al. (2013). WNT5A-NFAT signaling mediates resistance to apoptosis in pancreatic cancer. Neoplasia 15: 11-22.

Gunda V, Cogdill AP, Bernasconi MJ, Wargo JA, et al. (2013). Potential role of 5-aza-2'-deoxycytidine induced MAGE-A4 expression in immunotherapy for anaplastic thyroid cancer. Surgery 154: 1456-1462.

Hackert T and Buchler MW (2013). Pancreatic cancer: advances in treatment, results and limitations. Dig. Dis. 31: 51-56.

Han X, Tan ZJ, Guo RD, Li ZJ, et al. (2013). Effect of 5-aza-2'-deoxycytidine on growth and methylation of RUNX3 gene in human pancreatic cancer cell line MiaPaca2. Zhonghua Zhong. Liu Za Zhi. 35: 17-21.

Iwaya K, Ogawa H, Kuroda M, Izumi M, et al. (2003). Cytoplasmic and/or nuclear staining of beta-catenin is associated with lung metastasis. Clin. Exp. Metastasis 20: 525-529.

Jagou-Yuschak AF, Badra R, Ballario F, Montyn G, et al. (2013). Solid pseudopapillary tumor of the pancreas: a case report and a review of the literature. Acta Gastroenterol. Latinoam. 43: 139-142.

Jones S, Zhang X, Parsons DW, Lin JC, et al. (2008). Core signaling pathways in human pancreatic cancers revealed by global genomic analyses. Science 321: 1801-1806.

Mikysková R, Indrová M, Vlková V, Bieblová J, et al. (2014). DNA demethylating agent 5-azacytidine inhibits myeloidderived suppressor cells induced by tumor growth and cyclophosphamide treatment. J. Leukoc. Biol. [Epub ahead of print].

Morris JP, Wang SC and Hebrok M (2010). KRAS, Hedgehog, Wnt and the twisted developmental biology of pancreatic ductal adenocarcinoma. Nat. Rev. Cancer 10: 683-695.

Murtaugh LC, Law AC, Dor Y and Melton DA (2005). Beta-catenin is essential for pancreatic acinar but not islet development. Development 132: 4663-4674.

Nalls D, Tang SN, Rodova M, Srivastava RK, et al. (2011). Targeting epigenetic regulation of miR-34a for treatment of pancreatic cancer by inhibition of pancreatic cancer stem cells. PLoS One 6: e24099.

Vincent A, Omura N, Hong SM, Jaffe A, et al. (2011). Genome-wide analysis of promoter methylation associated with gene expression profile in pancreatic adenocarcinoma. Clin. Cancer Res. 17: 4341-4354.

Wang L, Heidt DG, Lee CJ, Yang H, et al. (2009). Oncogenic function of ATDC in pancreatic cancer through Wnt pathway activation and beta-catenin stabilization. Cancer Cell 15: 207-219.

Wang Q, Cai J, Cai XH and Chen L (2013). miR-346 regulates osteogenic differentiation of human bone marrow-derived mesenchymal stem cells by targeting the Wnt/beta-catenin pathway. PLoS One 8: e72266.

Wang S, Liu H, Akhtar J, Chen HX, et al. (2013). Alteration of runt-related transcription factor 3 gene expression and biologic behavior of esophageal carcinoma TE-1 cells after 5-azacytidine intervention. Asian Pac. J. Cancer Prev. 14: $5427-5433$ 